\title{
Web 2.0 collaboration tool to support student research in hydrology - an opinion
}

\author{
A. Pathirana ${ }^{1}$, B. Gersonius ${ }^{1}$, and M. Radhakrishnan ${ }^{2}$ \\ ${ }^{1}$ UNESCO-IHE Institute for water Education, Delft, The Netherlands \\ ${ }^{2}$ ARGHYAM, Bangalore, Karnataka, India \\ Correspondence to: A. Pathirana (a.pathirana@unesco-ihe.org) \\ Received: 23 January 2012 - Published in Hydrol. Earth Syst. Sci. Discuss.: 27 February 2012 \\ Revised: 12 June 2012 - Accepted: 19 June 2012 - Published: 6 August 2012
}

\begin{abstract}
A growing body of evidence suggests that it is unwise to make the a-priori assumption that university students are ready and eager to embrace modern online technologies employed to enhance the educational experience. We present our opinion on employing Wiki, a popular Web 2.0 technology, in small student groups, based on a case-study of using it customized to work as a personal learning environment $\left(\mathrm{PLE}^{1}\right.$ ) (Fiedler and Väljataga, 2011) for supporting thesis research in hydrology. Since inception in 2006, the system presented has proven to facilitate knowledge construction and peer-communication within and across groups of students of different academic years and to stimulate learning. Being an open ended and egalitarian system, it was a minimal burden to maintain, as all students became content authors and shared responsibility. A number of unintended uses of the system were also observed, like using it as a backup medium and mobile storage. We attribute the success and sustainability of the proposed Web 2.0-based approach to the fact that the efforts were not limited to the application of the technology, but comprised the creation of a supporting environment with educational activities organized around it. We propose that Wiki-based PLEs are much more suitable than traditional learning management systems for supporting non-classroom education activities like thesis research in hydrology.
\end{abstract}

\footnotetext{
${ }^{1}$ Here we use the term PLE to refer to the conceptual framework to make the process of knowledge construction a personalized experience - rather than to refer to the technology (in this case Wiki) used to attempt implementing such a system.
}

\section{Introduction}

With the rapid-phased entry of information and communications technology (ICT) into our lives, spearheaded by world wide web (WWW), the way we communicate, entertain and educate ourselves has changed dramatically over the last two decades. Educators assumed that the embracing of ICT by general public, particularly the young, has profound impacts on how the process of learning happens in formal environments like universities. Prensky (2001), in his muchcommented article, proposes: "the differences between our Digital Native students and their Digital Immigrant teachers lie at the root of a great many of today's educational problems". In the early stages of the "ICT in education" debate, it was claimed that today's university students are "... active experiential learners, proficient in multitasking, and dependent on communications technologies for accessing information and for interacting with others" (Oblinger and Oblinger, 2005; Bennett et al., 2008). However, many educators have questioned the validity of this assumption (Bayne and Ross, 2007; Bennett et al., 2008; among others). For example, the fact that the age group of 16-18 has been the dominant users of social networking does not necessarily translate into a more technology focused learning style at university stage (JISC, 2007).

In this context, we believe that ICT and WWW technology, particularly participatory web (Web 2.0), has to be employed in education with caution, without pre-conceived assumptions as regards to fitness-for-use in a particular domain and with an open empirical approach. In this paper, we present a case-study during which we applied a Web 2.0 technology (Wiki) to create a personal learning environment 
(PLE) to foster collaboration and learning in students engaged in master's level research in hydrology. We discuss the nature of the approach compared with traditional learning management systems (LMS), its challenges, proven benefits and the issues we encountered during its implementation over a five year period (2006-2011). We also extrapolate the findings to suggest other uses of the tested system in education.

\section{The problem}

\subsection{Thesis research in hydrology at UNESCO-IHE}

Studies on water are a multi-disciplinary problem: it has long been accepted that the science on which responses to present and future global water problems must be based does not fall within the purview of a single discipline but rather is multidisciplinary and transdisciplinary (Jury and Vaux, 2005). Most UNESCO-IHE thesis projects focus on problems that are of immediate practical importance and impact on human societies and the environment in a multitude of ways. This nature of our work challenges the students to venture into new areas not necessarily covered during coursework and to master them, sometimes even before starting the real application work. Taken along with the challenge of finishing the thesis project within the standard six months period, this imparts pressure both on the student and the supervisor and demands innovative didactic approaches.

Every year between 150 and 200 students enter UNESCOIHE as candidates of water related master's degrees. This is arguably the largest post graduate program on hydrology (in its broad sense) in the world (http://www.unesco-ihe.org). Students generally follow taught courses for a year and conduct research leading to a master's thesis during a period of six months. While the two phases are integral parts of the same degree programme, the skills needed from the students as well as approaches demanded from the faculty are quite different in each. As an organization UNESCO-IHE has identified the need of continuously improving the learning environment it provides to the students (Pathirana et al., 2012; Uhlenbrook and de Jong, 2012). A need to foster improved supervisory practices in thesis research has been identified in many graduate schools in the world (Acker et al., 1994; Aspland et al., 1999) and UNESCO-IHE also continues to strive to improve the effectiveness of the graduate thesis supervision process. The background of our students (see below) makes it important to pay even more attention to the process of conducting and supervising thesis research.

The majority of students of UNESCO-IHE are mid-career professionals who have been working in the sector (industry, government, academia, etc.) for at least two years (often much longer) after their bachelor's degree. Some students have produced an undergraduate thesis, but for many, the master's thesis at UNESCO-IHE is their first encounter with scientific research. The "distance" of memory of earlier university days also makes it difficult for some students to readjust to a life of formal learning and research - while a problem equally valid for coursework, it is felt more severely during the thesis period, when the students work on their own individual research project. Wide variations in competency levels in supporting skills like computer literacy (e.g. programming) within a single batch of students have also been noticed. Identifying this various preparatory activities are routinely organised (e.g. classes on literature search, computer programming, technical writing, etc.). However, the fact remains that we need and want to continuously and vigorously improve the process of thesis supervision process.

\subsection{A Theory $Y$ environment}

In the sixties, management psychologist McGregor (1960) identified two styles of management that he coined as Theory X: which assumed that the authorities had to actively direct the elements of productive enterprise without which the employees would be passive and even resistant to organizational change and Theory Y: which assume the employees seek and accept responsibility and the satisfaction of doing a good job is a strong motivation. Biggs and Tang (2007) proposed that the idea of Theory $\mathrm{X}$ and Theory $\mathrm{Y}$ climates transfer readily into the classroom. In this context Theory Y implies that students do their work best when given freedom and space to use their own judgement and that the bureaucratisation of the classroom is counterproductive for effective learning. This view gained popularity among educators during the last decade and is quite consistent with the theory of constructivism (see below) (Dawson, 2010). Theory $\mathrm{Y}$ approach has been shown to be quite successful in team building where individuals work is related and dependent upon their peers (e.g. Software engineering, Birkinshaw and Crainer, 2008). A brief look at the diverse nature of problems addressed in thesis research in water at UNESCO-IHE and the inter-linkages among research problems, approaches and techniques within a group of students suggest that it is a "Theory Y" environment that is desirable (even more so than in the classroom education) because such an atmosphere could stimulate both individual research and teamwork.

\subsection{Thesis research and social constructivism}

Constructivism, a broadly accepted theory on education states that humans learn by "constructing" knowledge in cognitive (personal process) and social (interaction with peers and teachers) domains (Powell and Kalina, 2009). Many studies have shown the benefit of Web 2.0 in the constructivist framework in classroom and distance education (Parker and Chao, 2007; Ullrich et al., 2008; Kawka, 2011).

In the context of thesis research, both cognitive and social constructivism theories can play a supplementing role. The "typical" thesis research process that includes interpreting 
literature and positioning it in one's own framework, planning and executing laboratory or numerical experiments, interpreting results, etc., places it somewhat in the cognitiveconstructivism domain. However, this can be effectively supplemented by activities that favour social constructivism. Examples are effective peer-communication, accessing others' knowledge and improving on this and (informal) peer-review.

While Web 2.0 (Sect. 2.4) can help in both these domains (Conole, 2008), it is the social aspects of the constructivist learning that can benefit most. The area of social constructivism known as "cooperative-learning" states that learning emerges through interaction of individuals with other individuals as individuals exercise, verify, solidify, and improve their mental models through discussion and information sharing (Lin and Hsieh, 2001). It is in this context that Web 2.0 really shines. For example, the participatory web provides a solid foundation for active participation. Web 2.0 tools also provides building blocks for an environment that enables multiple forms of support, as it allows people to connect, interact and share ideas effectively (Ozkan and McKenzie, 2008).

\subsection{A suitable web-based system}

The varied nature of thesis projects and skill sets needed make their activities, elements, milestones and goals quite unique and non-generic. We wanted to use web-based tools to activate peer-learning, which has been proven to be one of the most effective strategies in education (Biggs and Tang, 2007, p. 96, pp. 118-119). The basic requirements of the web-based system we envisioned for supporting a Theory Y learning Environment were:

- Could hold most (if not all) documentation (including multimedia content) related to each thesis project.

- Beginner friendly scheme where (accidental) destruction of information is virtually impossible.

- Highest possible degree of autonomy for the user.

- Controlled-entry to the system (not open to public) so that users feel comfortable having "work in progress" on it.

- Unrestricted access to all work (documents, computer programs, data, etc.) by peers in the group for the purposes of evaluating, learning from, and adopting for new purposes.

- A good search system and linking scheme so that the students can construct knowledge based on existing knowledge (Biggs and Tang, 2007, pp. 92-93).

Further we wanted to promote the following principles:

- Collaboration and team work which is very important for good research outcomes as well as an antidote to the inevitable stress of rapid-phased scientific research.
- Healthy competition among students to excel in their work.

- Users not being restricted in the way they express themselves on the system - so that their creativity is not restrained.

We already had access to two LMS systems, namely the inhouse "i-learning environment", which was the primary LMS of UNESCO-IHE at that time and a private Moodle installation used for experimentation. One of the challenges of adopting LMS for our purpose was to allow for the necessary freedom within the system. By necessity LMS are vertically integrated systems whose collaborative functions are secondary (e.g. Moodle has the ability to incorporate Wikis within a course). We decided to look beyond LMS.

\subsection{Web 2.0}

The term Web 2.0 is an example of a name preceding the definition: the term Web 2.0 started appearing in online sources largely since 2006 , but even a year later, there was a large disagreement over what it exactly meant (O'Reilly, 2007). Tim-Barnes Lee, the inventor of WWW called it just a "piece of jargon", on the grounds that what it tried to achieve was exactly the initial objective of the WWW - a collaborative medium where everyone could "read and write" (Laningham, 2006). However, today the term "Web 2.0" represents an approach that is user-centric, collaborative, decentralised and dynamic in knowledge building and sharing. The possibility for everyone to potentially participate in contributing and improving content is the key feature of Web 2.0 that we emphasize and exploited in the present experiment.

Web 2.0 is widely used in education today. Conole and Alevizou (2010) provides a detailed review of the practice in the Higher Education sector of the UK. There are numerous examples of applications of Web 2.0 in different fields of higher education (Luo, 2010; Kim et al., 2010; among others), each of which used one or several of the multitude of Web 2.0 features. For example Luo (2010) focuses on the power of Wiki systems in creating validated contents while, Cochrane and Bateman (2010), describes the use of richcontent (e.g. multimedia) in mobile media like Smart phones.

In the context of the current article, the focus has been on a few features of Web 2.0 namely, user centeredness, lack of hierarchy, dynamism and informal peer-review.

\subsection{LMS and Web 2.0}

Many universities today have a learning management system (LMS) that works as the primary content management system (CMS) for education (Popular implementations include Moodle, Blackboard and Chamilo). By nature LMS are vertically integrated and institutionally centralized (Mott, 2010). They are hierarchically managed, with careful access-control and have a strong structure. Web 2.0 tools (e.g. Wiki) are, on 
the other hand, loosely connected, highly-dynamic, decentralised systems. There are arguments that flexibility, portability, adaptability, and openness make Web 2.0 tools far superior to the LMS as a teaching and learning platform. It is important to understand that the two approaches are essentially two convenient locations on the continuum from steep hierarchy to user-centeredness.

A good analogy is the difference between a corporate web site and Wikipedia. By necessity, a corporate web site makes users essentially readers. This does not mean that users are not allowed to interact at all. They may be allowed to provide feedback, participate in (often moderated) blogs and chat rooms. However, the essence of the design is one of tightcontrol and hierarchy. One the other hand, on Wikipedia every single user is allowed to create and edit content and participate fully and completely in the construction of knowledge. Again, this does not mean that there are no entities who are "more equal than others". For example on Wikipedia there are (volunteer) editors who keep lookout for content vandalism and there are mechanisms (though not completely foolproof) to block blacklisted users from editing content.

There are convincing arguments for supplementing LMS with PLEs. For example: "Although the LMS needs to continue serving as an enterprise CMS [course/content management system], it also needs to be a student-cantered application that gives students greater control over content and learning. Hence, there is continual pressure for the LMS to utilize and integrate with many of the Web 2.0 tools that students already use freely on the Internet and that they expect to find in this kind of system. Some educators even argue that the next requirement is a PLE that interoperates with an LMS" (Agee et al., 2009; as quoted by Mott, 2010).

\subsection{The Wiki way}

One of the obvious candidates for the web-based system was a popular Web 2.0 tool - Wiki (Leuf and Cunningham, 2001; Parker and Chao, 2007; Svinicki and McKeachie, 2011, pp. 235-266). Salient features of a Wiki are (a) a Wiki invites all users to edit any page or to create new pages; (b) promotes meaningful topic associations by linking content within the system and with external resources (and; c) exist comfortably as an on-going process rather than a finished product.

There have been numerous attempts to employ Wiki's in higher education - some successful, others not. Kawka (2011) reports a four-year long experience in attempting to introduce Wiki to a first year university course. The author documents initial problems due to unfamiliarity of both students and the teacher with the Wiki approach. They emphasize the need for providing a good "scaffolding" support for the students in order for them to not to feel lost. Ebner et al. (2008) attempted to create a Wiki based on voluntary contributions. No student contributed to the Wiki though many used it passively, and a subsequent survey indicated that the majority of the students saw it as a complicated, timeconsuming or useless task to contribute to the Wiki. They concluded that application of the Wiki in an educational setting is much more complicated and "it needs more time to develop a kind of "give-and-take" generation". Cole (2009) reported a failed attempt to introduce Wiki into the subject matter of a third year undergraduate module in the Brunel University, UK. One of the interesting findings from this study is that while students are willing to do passive activities online (viewing, reading), when it comes to active contribution (writing, uploading) they are reluctant for various reasons. We discuss our experience on this point later in this paper.

In the recent literature suggestions have been made on using Wiki as a tool for managing research groups and (student) research projects (Sauer and Bialek, 2005; Duffy and Bruns, 2006; Parker and Chao, 2007; Li et al., 2010; among others). However, there is little empirical observation on how these work in practice in the research group/project context.

By the end of 2006 there had been a proliferation of Wiki frameworks to choose from. We selected MediaWiki the open-source software Wikipedia runs on (Wikipedia, 2011; Barrett, 2008). We already had some experience in using MediaWiki for non-standard uses (Pathirana, 2006a, b). The major modifications have been done to prevent content from being open to the public (password protection) for reading and editing. Technically this has been a simple objective to achieve (Pathirana, 2006b; Barrett, 2008). We implemented the system on a dedicated Linux server hosted in-house. The technical requirements of maintaining the system have been minimal. We performed upgrades to the Wiki software and the LAMP-stack (Linux operating system, Apache HTTP Server, MySQL database software and PHP language) approximately once a year, due to security concerns. Other than that there was no technical burden running the system during the five year period. Due to the non-public nature of the solution, security concerns are also not nearly as high as public web services.

\section{A five-year experiment}

The Web 2.0-based system (see Fig. 1) was first introduced to the students on 22 December 2006. The selected group of students were from the department of urban water and sanitation. Every year in September (when the students are about to start their research) the system was opened to a new group of students as follows: First, a two-hour tutorial was conducted to introduce the system and guide the users through the basic use (reading, searching, editing and content uploading, internal and external (web) linking). After that each user was issued a password to access the Wiki. The users were asked to do the following throughout their thesis period:

- Every student maintains their own user page where primary information on the thesis project is kept. However, the user can create any number of other pages if needed. 


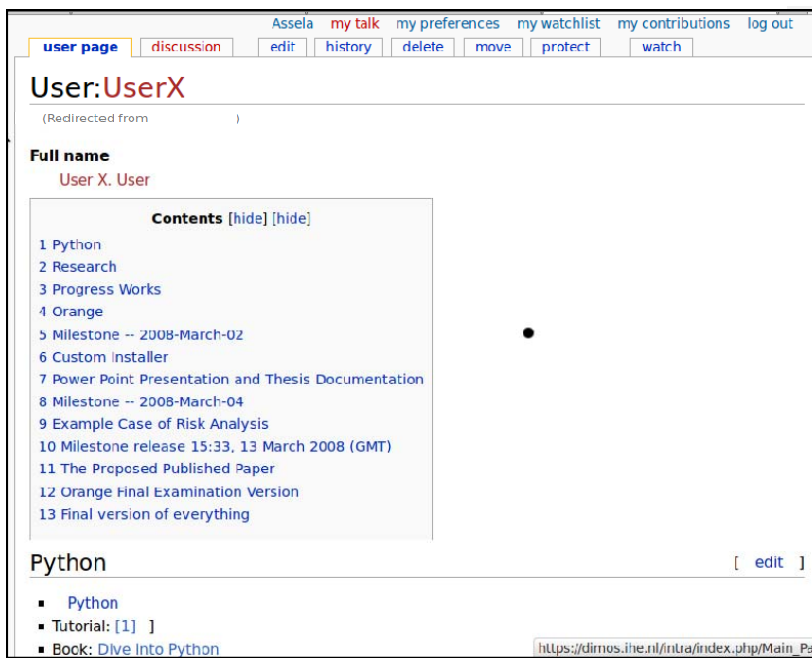

Fig. 1. The top portion of a user page (A Student from 2007-2008 group).

- Before each meeting with the supervisor, each student should either write down or upload the material for the discussion (e.g. a computer model for review, a summary of a research article read or a description of a case-study). After meetings students were encouraged to write a summary of the meeting.

- Whenever students make presentations, they upload the slides to the Wiki.

- Access other students' pages for reference material and comment on them.

- Resources like model configurations, computer programs, data, etc. are kept uploaded in the system.

\subsection{A process more than the product}

We emphasized the importance of seeing the Wiki as a process rather than as an end product. Students have been encouraged to create content that describes "products" that are not yet complete (e.g. Ideas that need further thinking, Models with problems running, computer programs needing more improvement, draft versions of presentations). This was a difficult habit to cultivate and needed frequent reminders. For example it had been common for students during their first few months to resist uploading a presentation because "it is yet to be shown to the supervisor".

\subsection{Linking knowledge}

One of the distinct advantages of using a Wiki is the ease with which related information could be linked. External links can be created to various WWW resources. Internal links can be made to other pages or specific locations of those pages. We employ internal links for three main purposes: (a) linking to "authoritative sources" (e.g. a tutorial created by a user and peer reviewed); (b) linking to past work (e.g. a related thesis project done in a previous year); and (c) organizing information in "meta-pages" (e.g. a page listing all the projects of year 2008).

\subsection{A supporting environment}

A mere technical framework would not have achieved our objective-principles of healthy competition and teamwork, leading to effective learning (Smith 2008, p. 58; Kingston et al., 2012). The planned regular educational activities revolved around the Wiki and reinforced these principles. On average at biweekly frequency, group meetings have been organized where all students presented their research progress and discussed the problems. All students were encouraged to think about their colleagues' problems and suggest possible solutions. In almost every meeting one or two students were invited to make longer (15-20 $\mathrm{min}$ ) presentations on their research achievements. All these meetings were organized in a very informal setting, more like platforms for "thinking out loud" and exchanging ideas than to deliver formal presentations. More often students presented problems and issues than solutions and invited peers to suggest solutions.

Most of the students in these groups were involved in mathematical modelling of urban hydrological/hydraulic problems. Many of the highly-recurrent issues were of a technical nature: (a) issues to do with computer programming; and (b) advanced use of modelling software. Since 2007, an annual four-day seminar on advanced computer programming (known as "programming boot camp") has been conducted. The entire learning resource (a self-study tutorial of around 90 pages and numerous case-studies) of this activity had been developed on the Wiki system with the collaboration of students. Every year we solicited the contribution of the students to enlarge and improve this material.

There have been many technical issues related to modelling that were common for many research projects (one typical example being how to programmatically link an urban hydrological model to an optimization algorithm and a simple financial model). In these situations we reaped maximum benefits of having a Wiki system. Typically a teacher helps a student to solve this problem. Then we invite the student to author an article on the Wiki on how to solve the particular problem. The future students were simply guided to the article and were asked to improve it as they solved their own (related) problem.

On many occasions a number of master's research projects are being planned in sequence: a thesis completed in a given year may feed in as the starting point of a thesis in the next year. As an example: the first thesis focuses on the development of a coupled 1-D/2-D hydraulic model suitable for modelling urban flood inundation problems. In the second year a student would use the model to couple it with an 
optimization algorithm to solve a risk-based urban drainage design problem. The Wiki provided a natural framework of continuity for such situations. The second student would start off by linking the resources from the predecessor to their own page, reviewing them and understanding how they work (all these steps are recorded on the Wiki).

The membership of a user is not revoked after the user leaves the institute. Many graduates continue to access the Wiki as a resource to refer to their own research work and to those of the colleagues, which may help solve some current problem.

There are no restrictions on what a user can do inside the Wiki. Everyone can edit any page, add new pages or alter any material. The system is based on trust - everyone respecting the guidelines. However, everything that is being done on the system has been recorded, so that if a mistake happens (e.g. deleting a page, uploading the wrong document) it is extremely easy for others to correct it. We follow the operating principles of Wikipedia. While this may sound like a risky policy, it becomes a manageable one due to two reasons: the robust version control system in MediaWiki provides the means for any user to see and restore any version of a document that is online. For example if student A uploads their thesis and student B "overwrites" that by uploading some unrelated document, any user of the system can "recover" the old document just by a few mouse clicks. During the reported five year period, not a single incident of vandalism happened. There were several unintended incidents of overwriting documents, but they were immediately corrected by a user.

\subsection{The growth of the system}

We have collected statistics on the use and growth of the Wiki over the five year period (2006-2011). Every year around ten to fifteen students are being added to the system (see the Supplement), currently we have 89 accounts, including the teaching staff involved. There has been almost a linear growth of content (see the Supplement) over the period resulting in around 2500 different pages as of November 2011. As shown in Fig. 2, the user activity shows a bimodal annual pattern, which can be explained with the nature of the progress of a typical thesis project. The first peak (September-October) signifies the starting period of the thesis where students prepare a proposal, do a literature survey (they upload all their literature to the Wiki) and defend the proposals. The second peak (January-March) is the period when many students obtain significant results (which they upload to and discuss in the Wiki), write the bulk of the thesis (again, they keep all the work in progress as well as the final copy on the Wiki) and prepare for the defence. Currently the system achieves around 2800 files in total size about 24 GB of data (see the Supplement).
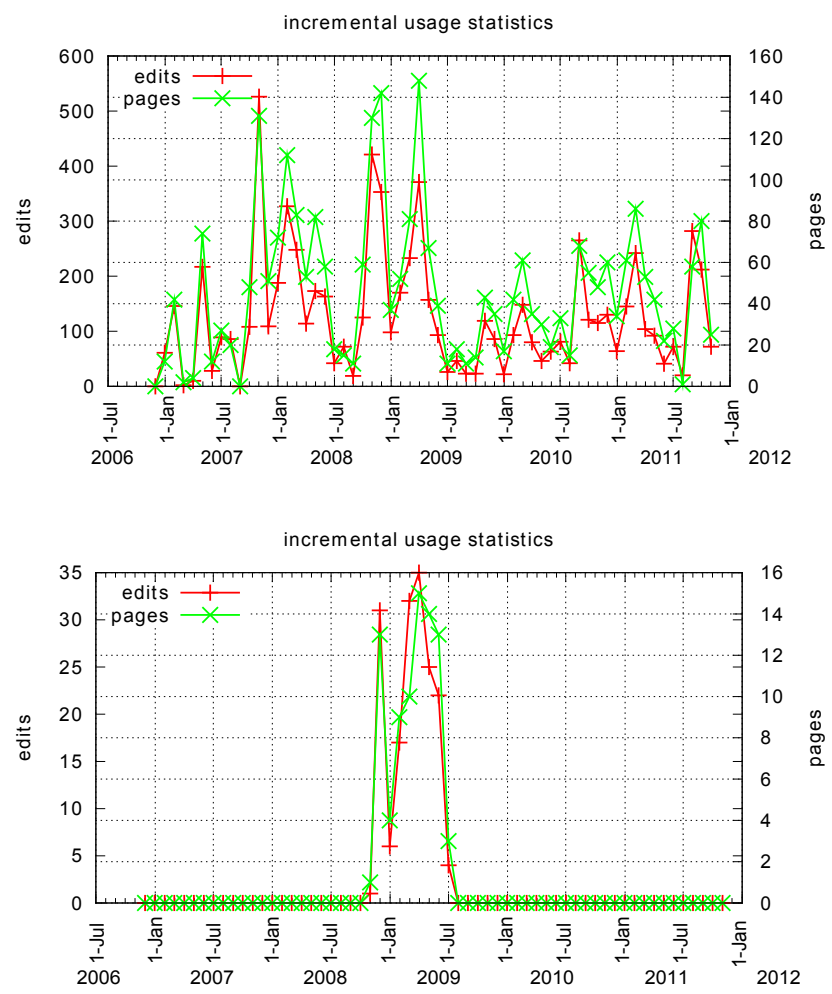

Fig. 2. Monthly breakdown of new pages and edits (top). Activity report for a single user (A student from the group 2008-2009) (bottom).

\subsection{Evidence for cross referencing}

One of the important goals of the Wiki system is to encourage subsequent users to refer to already completed work. In order to demonstrate this use of the system, we present the cases of two students:

Student A did research from September 2008 to April 2009, on "Optimal Planning of a Water Distribution Network for the Developing World using Criticality Theory", using a case study from Minneriya town, Sri Lanka. Large amounts of data from the study site, which included, hydraulic properties of the water distribution system and material and other asset data (including failure information) of the network assets, were collected by the student. A new calculation algorithm for improved simulation of drinking water networks under sub-optimal operating conditions was developed. Later, a number of students based their thesis work on these two sources, namely, the data and the new algorithm.

Student B developed a Multi-Objective optimization framework for her research entitled "Development and Application of Urban Flood Risk Management Decision Support Tool using Multi-Objective Optimization", by integrating a 1-D dynamic flood simulation model with an efficient 
multi-objective optimization algorithm (October 2008 to April 2008). Several students subsequently utilized her framework as the basis for their own flood related optimization work.

Figure 3 shows the number of page and file downloads from those two user's pages in the period March 2010 to January 2012. This figure shows one of the important aspects of the system, namely, how students use their predecessors' findings as the basis for their own construction of knowledge.

\section{Emergent uses of the Wiki}

The primary and intended use of the Wiki system has been to serve as a platform of academic information construction and sharing. The system increased the efficiency of both the students and the faculty involved in the supervision. At the same time, some atypical uses of the system also emerged over the years.

\subsection{A medium of backup}

Keeping regular backups of work in progress has been an important task, often forgotten by computer users. From the beginning it has been observed that some students started using the Wiki system as a convenient place to keep a backup copy of their work in progress. Later this was actively encouraged and some barriers for such use (e.g. limit of maximum upload size) have been removed. One of the salient features of the practice being the fact that making backups became a part of regular work and communication with their peers (e.g. uploading a draft of the thesis serves the dual purpose of sharing it with your group for comments as well as its safe-keeping). Recognizing the importance of this role, we started making off-site automated backups of the entire Wiki, making it one of the safest places in the institute to store information.

\subsection{A permanent archive}

Every student has been asked to keep a digital copy of their draft-thesis and the full set of working data and techniques on the Wiki during the entire period of finalizing their work. Without any extra effort, the final snapshot of these materials is being left on the system when the student leaves the institute. Very soon the Wiki became the primary source for the supervisors involved and subsequent students to find reports and material on past studies.

\subsection{A mobile storage}

Many users started using the system as a mobile storage. When they move between computers (e.g. at the campus and at home) and visits overseas on field data collection missions, the Wiki helped them to seamlessly access the latest version of their work in progress. Graduate students routinely use the Wiki to access information for later use. Past users

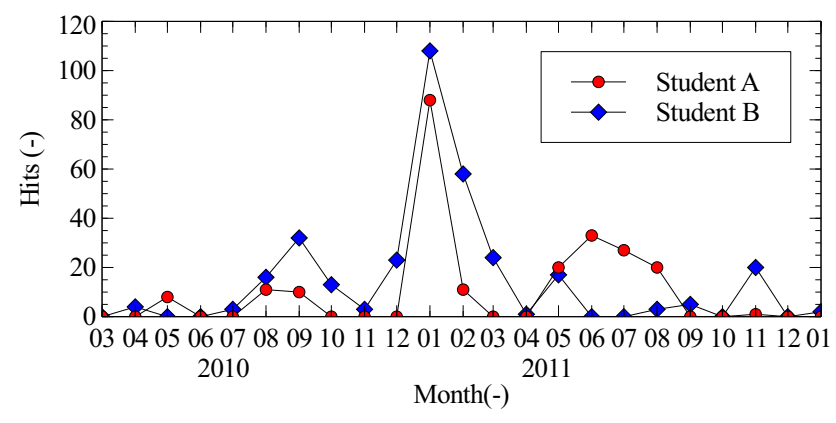

Fig. 3. Downloads of material from pages of Student A and Student B (2008-2009) the period March 2010 to December 2011, by other students.

commented that they have utilized this function of the system when they travel and when they are in need of access to past work to discuss with a stakeholder or a fellow researcher.

\section{Impressions of the students and educators}

\subsection{Students' impressions}

In the fourth year since the opening the Wiki (year 2010), we sent a questionnaire on the process of master's degree supervision to the group of five students graduated in the year 2008-2009. This questionnaire included the following question regarding the Wiki system: "We used a Wiki system for storing information and communications within the group. Did this help you? Was it a distraction? Give your views". Overall the students' comments on the Wiki were positive (see the Supplement). One respondent said "I believe that Wiki system made the learning and research processes very simple. It contains most important software tools, module/course work materials and reference publications and works done by the students and staff members. This allowed us to exchange thoughts and materials efficiently. It also kept us on track with what has been done by the other members. In addition it encourages the spirit of team research work. Simple ideas are sometimes the most difficult thing that hold-up the progress on the research work. However, the WIKI system gave us the opportunity to know with whom to discuss whenever we face any challenges during our work".

While this feedback has not been a part of a scientific survey, it gave us the indication that the users were satisfied with the Wiki system and continue to recommend it after they have finished their studies at UNESCO-IHE.

\subsection{Educators' impressions}

Feedback from graduated students indicated that they liked the employment of Wiki in the thesis research phase. However, it was very rare that the students liked to use the Wiki system from the beginning. In fact, in every year most of the 
students appear to start using the Wiki due to persuasion (before the first peak) of the supervisors. Techniques described in Sect. 3 have been commonly employed to get the students to use the system gradually in spite of the natural resistance shown by many to try an unfamiliar approach. Almost all students have read articles on Wikipedia - but most were just "readers" and did not comprehend how it worked as a social medium of knowledge construction. While the initial training sessions (Sect. 3) have been helpful to get the students started on usage, few were convinced of its utility until they tried it for a month or so. The second peak (February-March) occurred without encouragement from the supervisor; by this time the students have become used to the system and have realized some of its benefits by experience.

Another important aspect of the Wiki system was that it demanded negligible time-involvement from the supervisors, beyond the normal supervision activities. In fact, some features (e.g. immediate availability of the latest results of a student) worked to save time and increase overall efficiency. It also encouraged peer to peer learning which enabled wider problem solving and dialogue rather than approaching the mentor immediately in case of doubts and apprehensions.

\section{Discussion}

Over the last five years a specialized Wiki has been employed to manage the process of thesis research in water. This has been a good point in time to look back and take stock of the experiences and share the findings with other hydrology educators.

Embarked upon as an open-ended experiment in 2006, we are now convinced of the possibility of employing modern ICT tools, like Web 2.0, in water education. However, we did not make the a-priori assumption that our students are from the fabled "Net-generation" and that the use of Web 2.0 tools (Wiki in the present case) is a necessary response to fill a generational gap between educators and students. Perhaps the demography of our students (mid-career professionals from water organizations of the developing world) prevented us from making that assumption. In this respect, one of the most important reasons why the proposed Web 2.0based approach has been successful is that we never assumed that the students are well-versed in the art of the collaborative web. Rather, we strived to create an environment where the students gradually familiarised themselves with the system and the benefits of its use. This, in our view has been a key element for success in introducing innovation in education.

We introduced an open ended and largely egalitarian system. The system has not been driven by a few to be "used" by the rest. By nature, Wikis follow a participatory approach that has been leveraged in this specific application. Every user has been allowed to express their own style for content creation; moreover, the educators have never interfered with the way students created content.
The above experience confirms the place PLEs could play in addition to LMS in today's higher education. While, for some applications the vertically integrated nature of LMS is very much needed, we wish to point out that the flexibility that has been needed to allow the students to express themselves freely has often been lacking in typical LMS systems, unless they are supplemented by user-centric tools like Wikis. Managing thesis research in hydrology, the current case study is an example: We have been dealing with broad and diverse problems that need transdisciplinary scientific approaches to solve; the process of education should reflect this diversity in real-world and the tools employed should be flexible to support this. Based on our experience during this study, we stress the appropriateness of Web 2.0 (user-centric) techniques in this context.

Employment of ICT in water education is an important means to improve the overall educational experience. However, mere use of it does not necessarily make education a more effective and student-centred process. What matters more are the underlying principles of an educational environment. In this context technological innovation has been just one of many aids that helps to implement those principles. In the present case these were: (1) collaboration; (2) healthy competition; and (3) freedom of expression within a secure environment. We have deployed a specialized Wiki system as a tool to help achieve these objectives. At the same time, we have organized a number of related activities (e.g. frequent informal meetings, various tutorials for common problems) around the existence of the Wiki. It was this integrated environment that made the concept work, rather than just the technological approach taken.

The Wiki system encouraged the collaboration among students very effectively: The group of students very soon become a community where each person knows what others do - both scientific research and set of specific skills (e.g. use of a particular hydrological model) they are developing to achieve their objectives. First the group meetings introduce them to each others' worlds. But the presence of a current snapshot of everyone's work on the Wiki solidifies this understanding. Every year we observe the collaboration naturally arising within this context, with some help from the educators. For example, students had started asking for help from each other and discussing their problems on their own initiative.

\subsection{Beyond LMS}

What is the need to introduce Wikis in an educational environment which may already have a fully-fledged LMS system? We already have discussed some of the differences of Web 2.0 PLEs and LMS in Sect. 2.5 above. There are some distinct benefits of deploying Wiki-based PLEs in terms of knowledge construction that became apparent during this study. LMS systems are generally organized in a course based structure. While an LMS like Moodle is technically 
capable of hosting Wikis, these are components of specific courses. However, via the use of both these systems during the last five years - Wiki for the purpose of thesis research, Moodle for classroom teaching - we are convinced that Wiki has several important advantages for the purposes described in this manuscript, which include:

1. Wiki promotes an egalitarian spirit - everyone is equal within the system.

2. With features like automatic-version control and logging of all activity, Wikis are more robust to deploy in an unrestricted context.

3. Wiki facilities in LMS (e.g. Moodle) are components of a course. They are designed to be deployed over the duration of the course and to be archived upon conclusion of the course (so that the next duration of the course can be started afresh).

Clearly none of these "disadvantages" of LMS are impossible to overcome. However, this implies significant customization of the system and could lead to a larger administrative burden. On the other hand, Wikis are designed to provide these functionalities.

We fully agree that for classroom use and for distance education, LMS like Moodle are the appropriate tools. However, we argue that there are distinct advantages in using Wiki over LMS for supporting student research groups.

\subsection{Social networking and Wiki}

Students and teaching staff alike use social networking tools like Google Docs (file sharing), Facebook (networking) and Twitter (messaging). An important advantage of using such off-the-shelf solutions is the low-entry barrier to the students as many of them are already familiar with such services. It is indeed possible to provide some of the (technical) facilities provided by the Wiki system using these tools, although there may not be a single tool that can provide all the important roles of the Wiki. However, bigger concerns include the (perceived and real) issues to do with privacy, difficulty in providing a coherent access control and the complete lack of integration. These issues are possible to overcome and there are already many studies on using social networks for education (e.g. Ozkan and McKenzie, 2008; Roblyer et al., 2010).

\subsection{Limitations and generalizations}

Our application of the Wiki system was done in a very specific context: While the research problems have been diverse, most of the students were using modelling tools in their work. There have been several modelling tools (e.g. hydrological models, network-hydraulic models) and other techniques (e.g. Evolutionary algorithms for optimization) that have been commonly used by many students. This context made the system more effective - for example in terms of collaboration among students. A question that arises is whether this approach can be used outside this specific context.

In our opinion another area that can benefit from this work is research groups focused on laboratory experiment based research. Whether it is hydraulic/hydrological lab work or water technology experiments, there are a number of skills the students need to develop while engaged in lab work. While the research themes change, many of these skills change much more slowly making it quite useful to record past experiences for the benefit of the future users.

Our (limited) experience in using this system for casestudy based research, where the student travels to a remote location to conduct field work, did not produce encouraging results. There have been situations where slow internet connections were inadequate to use the system effectively. However, even in cases where the latter has not been an issue, we have noticed that the students' use of the system is often not sustained throughout a period of long absence from the group. We attribute this behaviour to the importance of other ingredients and a total integrated environment (e.g. frequent meetings where students meet each other face to face).

Can this approach be applied to a group of any size? While we do not have information to conclusively state, it is our opinion that the system works only as long as the group is small enough for the members to know each other personally (maximum 10-15?). This is quite suitable to manage a typical "research group" in hydrology with one or two scientists and a number of graduate students. The best way to deploy such a system for a typical educational department is to organize a series of clustered, but completely independent sets of wikis - one for each group.

From a technical point of view, apart from MediaWiki, there are many comparable Wiki systems that can be used for this type of application. In fact, some of them could be more suitable for "private" Wiki systems like the one presented. For example DokuWiki or PmWiki provides the access-control mechanisms (allowing only password-based access) by default.

\section{Conclusions}

In this paper we have presented a five-year case-study of using Web 2.0 technology (Wiki) in the context of thesis research management in hydrology. Properly supplemented with suitable supporting activities, this approach can provide a framework that fosters collaboration, healthy competition and unrestricted thinking and expression - elements that are essential for work solving substantial water problems - in the students. We conclude the following:

1. Employment of Wikis is an excellent way of building research groups in thesis research in hydrology. 
2. The deployment of new technology is but one ingredient to establish an effective learning environment. An integrated environment of activities geared towards this objective, that feed and nourish each other is needed to effectively strive for this goal.

3. PLEs have an important place in hydrology education in managing graduate research.

\section{Supplementary material related to this article is available online at: http://www.hydrol-earth-syst-sci.net/ 16/2499/2012/hess-16-2499-2012-supplement.zip.}

Acknowledgements. We acknowledge Corrie de Haan and Richard Ashley who read the draft versions of the manuscript and contributed with a number of improvements. We thank all the students and staff members who participated in this experiment. The comments of the two reviewers and the handling editor helped us to improve this paper.

Edited by: S. Uhlenbrook

\section{References}

Acker, S., Hill, T., and Black, E.: Thesis supervision in the social sciences: Managed or negotiated?, Springer Netherlands, High. Educ., 28, 483-498, doi:10.1007/BF01383939, 1994.

Agee, A. S., Yang, C., and the 2009 EDUCAUSE Current Issues Committee: “Top-Ten IT Issues, 2009”, (July/August 2009), EDUCAUSE Review, 44, 44-59, 2009.

Aspland, T., Edwards, H., O'Leary, J., and Ryan, Y.: Tracking New Directions in the Evaluation of Postgraduate Supervision, Springer Netherlands, Innovative Higher Education, 24, 127147, doi:10.1023/B:IHIE.0000008150.75564.b3, 1999.

Barrett, D.: MediaWiki, O'Reilly Media, 1st Edn., 384 pp., available at: http://www.amazon.com/ Mediawiki-Wikipedia-Beyond-Daniel-Barrett/dp/0596519796, 2008.

Bayne, S. and Ross, J.: The "digital native" and "digital immigrant": a dangerous opposition. Annual Conference of the Society for Research into Higher Education (SRHE) December, available at: http://www.malts.ed.ac.uk/staff/sian/natives_final.pdf (last access: 6 August 2012), 2007.

Bennett, S., Maton, K., and Kervin, L.: The "digital natives" debate: A critical review of the evidence, Brit. J. Educ. Technol., 39, 775-786, doi:10.1111/j.1467-8535.2007.00793.x, 2008.

Biggs, J. and Tang, C.: Teaching for Quality Learning at University (Society for Research Into Higher Education) Open University Press, 360 pp., 2007.

Birkinshaw, J. and Crainer, S.: Game on: Theory Y meets Generation Y, Wiley Online Library, Business Strategy Review, 19, 4 10, 2008.

Cochrane, T. and Bateman, R.: Smartphones give you wings: pedagogical affordances of mobile Web 2.0, Australasian Society for Computers in Learning in Tertiary Education, Australas. J.
Educ. Tec., 26, 1-14, available at: http://shura.shu.ac.uk/3541/1/ editorial26-1.pdf, 2010.

Cole, M.: Using Wiki technology to support student engagement: Lessons from the trenches, Comput. Educ., 52, 141-146, 2009.

Conole, G.: New Schemas for mapping pedagogies and technologies, Ariadne, available at: http://www.ariadne.ac.uk/issue56/ conole/ (last access: 1 June 2012), 2008.

Conole, G. and Alevizou, P.: A literature review of the use of Web 2.0 tools in Higher Education Table of Contents, Methodology, Walton Hall Milton Keynes, available at: http://oro.open.ac.uk/ 23154/ (last access: 6 August 2012), 2010.

Dawson, J.: Honouring Diversity through Constructivist GroupBuilding, Procedia - Social and Behavioral Sciences, 7, 210 218, doi:10.1016/j.sbspro.2010.10.030, 2010.

Duffy, P. and Bruns, A.: A conversation of possibilities, World Wide Web Internet And Web Information Systems, 31-38, 2006.

Ebner, M., Kickmeier-Rust, M., and Holzinger, A.: Utilizing WikiSystems in higher education classes: a chance for universal access?, Universal Access in the Information Society, 7, 199-207, doi:10.1007/s10209-008-0115-2, 2008.

Fiedler, S. and Väljataga, T.: Personal learning environments: concept or technology?, International Journal of Virtual and Personal Learning Environments, 2, $11 \mathrm{pp}$., doi:10.4018/jvple.2011100101, 2011.

JISC: Student expectations study, Key findings from online research and discussion evenings held in June 2007 for the Joint Information Systems Committee, Study Conducted by Ipsus MORI 2007.

Jury, W. A. and Vaux, H.: The role of science in solving the world's emerging water problems, P. Natl. Acad. Sci. USA, 102, 1571515720, doi:10.1073/pnas.0506467102, 2005.

Kawka, M.: Wrestling and Wrangling with a Worrisome Wiki?: An Account of Pedagogical Change in the use of a Web 2.0 technology in a First Year Education Course, Studies in Learning, Evaluation, Innovation and Development, 8, 38-48, 2011.

Kim, J. Y., Gudewicz, T. M., Dighe, A. S., and Gilbertson, J. R.: The pathology informatics curriculum Wiki: Harnessing the power of user-generated content, Medknow Publications and Media Pvt. Ltd., Journal of Pathology Informatics, 1, 10, doi:10.4103/21533539.65428, 2010.

Kingston, D. G., Eastwood, W. J., Jones, P. I., Johnson, R., Marshall, S., and Hannah, D. M.: Experiences of using mobile technologies and virtual field tours in Physical Geography: implications for hydrology education, Hydrol. Earth Syst. Sci., 16, 1281-1286, doi:10.5194/hess-16-1281-2012, 2012.

Laningham, S.: developerWorks Interviews: Tim Berners-Lee, available at: http://www.ibm.com/developerworks/podcast/dwi/ cm-int082206txt.html (last access: August 2012), 2006.

Leuf, B. and Cunningham, W.: The Wiki way: quick collaboration on the Web, 464 pp., Addison-Wesley Professional, 2001.

Li, N., Ullrich, C., Helou, S. E., and Gillet, D.: Using social software for teamwork and collaborative project management in higher education, Lect. Notes Comput. Sc., 161-170, 2010.

Lin, B. and Hsieh, C.: Web-based teaching and learner control: a research review, Comput. Educ., 37, 377-386, doi:10.1016/S03601315(01)00060-4, 2001

Luo, L.: Web 2.0 Integration in Information Literacy Instruction: An Overview, J. Acad. Libr., 36, 32-40, doi:10.1016/j.acalib.2009.11.004, 2010. 
McGregor, D.: I960. The Human side of enterprise, New York: McGraw-Hill, 246 pp., McGraw-Hill Inc., US, 1960.

Mott, B. J.: Envisioning the Post-LMS Era: The Open Learning Network. EDUCAUSE Quarterly, 33, 1-8, 2010.

O'Reilly, T.: What Is Web 2.0: Design Patterns and Business Models for the Next Generation of Software, Communications Strategies, 1, p. 17, 2007.

Oblinger, D. and Oblinger, J.: Is it age or IT: first steps towards understanding the net generation, in: Educating the Net generation, edited by: Oblinger, D. and Oblinger, J., 2.1-2.20, Boulder, CO, EDUCAUSE, 2005.

Ozkan, B. and McKenzie, B.: Social Networking Tools for Teacher Education, in: K. McFerrin et al. (Eds.), Proceedings of Society for Information Technology \& Teacher Education International Conference 2008, 2772-2776, Chesapeake, VA: AACE, 2008.

Parker, K. R. and Chao, J. T.: Wiki as a Teaching Tool, Learning, 3, 57-72, 2007.

Pathirana, A.: A Productive Desktop Environment for Scientists and Engineers - Part IV, available at: http://assela.pathirana.net (last access: 23 November 2011), 2006a.

Pathirana, A.: MediaWiki for personal webs available at: http: //assela.pathirana.net (last access: 23 November 2011), 2006b.

Pathirana, A., Koster, J. H., de Jong, E., and Uhlenbrook, S.: On teaching styles of water educators and the impact of didactic training, Hydrol. Earth Syst. Sci. Discuss., 9, 2959-2986, doi:10.5194/hessd-9-2959-2012, 2012.

Powell, K. C. and Kalina, C. J.: Cognitive and social constructivism: Developing tools for an effective classroom, Education, 130, 241-251, available at: http://edci6304sp2011.pbworks.com/ w/file/fetch/37550917/COGNITIVEANDSOCIALErika.pdf, 2009.
Prensky, M.: Digital Natives, Digital Immigrants Part 1, On the Horizon, 9, 1-6, doi:10.1108/10748120110424816, 2001.

Roblyer, M., McDaniel, M., and Webb, M.: Findings on Facebook in higher education: A comparison of college faculty and student uses and perceptions of social networking sites, Internet High. Educ., 13, 134-140, 2010.

Sauer, I. and Bialek, D.: "Blogs" and "wikis" are valuable software tools for communication within research groups, Artif. Organs, 29, 82-83, 2005.

Smith, R. M.: Conquering the content: A step-by-step guide to online course design, Jossey-Bass Inc. Pub., 6, p. 153, 2008.

Svinicki, M. and McKeachie, W. J.: McKeachie's teaching tips: Strategies, research, and theory for college and university teachers, Wadsworth Cengage Learning (distributed at the beginning of the course), Additional articles will be added in due course, Charge for admission, Wadsworth Pub Co., 2011.

Uhlenbrook, S. and de Jong, E.: T-shaped competency profile for water professionals of the future, Hydrol. Earth Syst. Sci. Discuss., 9, 2935-2957, doi:10.5194/hessd-9-2935-2012, 2012.

Ullrich, C., Borau, K., Luo, H., Tan, X., Shen, L., and Shen, R.: Why Web 2.0 is Good for Learning and for Research?: Principles and Prototypes, 17th International World Wide Web Conference, Beijing, China, 2008.

Wikipedia contributors: "MediaWiki:Cite text", Wikipedia, The Free Encyclopedia, available at: http://en.wikipedia.org/w/index. php?title=MediaWiki:Cite_text $\backslash$ \&oldid=456237747 (last access: 25 November 2011), 2011. 